\title{
RECONFIGURAÇÓES DA TEORIA SOCIAL APÓS A HEGEMONIA OCIDENTAL
}

\section{Wolfgang Knöbl}

DOI: http//dx.doi.org/10.17666/308705-17/2015

Nas últimas três décadas, os cientistas sociais tiveram de aprender que os pressupostos a respeito da robustez e da estabilidade de processos e estruturas sociais não podem mais ser tidos como autoevidentes, pois os resultados das açóes sociais são muito mais imprevisíveis do que usualmente se supóe, e que os eventos e sua ocorrência surpreendente precisam ser levados em conta para se entender a realidade social. Se assim é, então a teoria social precisa repensar alguns de seus pressupostos metodológicos e teóricos fundamentais. Este artigo abordará as seguintes questóes: de que teoria da ação se necessita para lidar com as características contingentes da vida social? Que tipos de explicação os cientistas sociais podem dar para compreender essa mesma realidade? Eles podem falar com segurança em leis e/ou mecanismos sociais gerais, ou precisam antes valer-se de métodos narrativos? A resposta princido em Caxambu-MG, em outubro de 2014. pal dada a essas questóes será a de que, na verdade, a teoria social precisará lidar com o problema da "narratividade", o que ao mesmo tempo também quer dizer que a corrente dominante da teoria social terá necessariamente que historicizar por completo todas as suas categorias. Argumenta-se que, se essa tarefa for assumida seriamente, poderá surgir, então, um intercâmbio frutífero entre os enfoques "tradicionais" das ciências sociais, por um lado, e o pensamento pós-colonial, por outro.

"As ciências sociais encontram-se em uma fase de transição". Tal afirmação pode certamente justificar-se com relação a indicadores institucionais, na medida em que é notável o quão rapidamente a posição dominante dos acadêmicos europeus ocidentais e norte-americanos se desvaneceu nas duas últimas décadas e o quão importantes se tornaram os intelectuais não ocidentais, e não menos os do Brasil e da América Latina. A globalização teve, assim, um enorme impacto sobre a estrutura das 
ciências sociais. Mas há mais coisas envolvidas aqui do que simplesmente mudanças institucionais ou organizacionais, pois novas abordagens estão também claramente desafiando algumas das premissas mais básicas do pensamento social "ocidental”. Assim, parece estar igualmente em processo uma mudança teórica e conceptual significativa.

Embora não se deva esquecer que, mesmo no apogeu da hegemonia ocidental, a ciência política, a sociologia, a antropologia e mesmo a economia nunca foram disciplinas monoparadigmáticas - e as batalhas intelectuais entre, digamos, abordagens hermenêuticas e qualitativas, por um lado, e tradiçôes de pesquisa funcionalista, neoutilitarista e quantitativa, por outro, foram consideravelmente virulentas -, as recentes mudanças constituem mais do que simplesmente uma continuação dos debates ocorridos nas décadas de 1960, 1970 e 1980. Isso se deve especialmente a duas razóes. Em primeiro lugar, mudanças muito importantes nas estruturas do mundo causam atualmente enormes dificuldades para os cientistas sociais ocidentais que ainda querem usar seus instrumentos analíticos tradicionais, que ainda se aferram a suas premissas teóricas. Entretanto, cada vez mais, eles têm que se defrontar com o fato de que a "realidade" parece ridicularizar seus conceitos e hipóteses. Enquanto, até os anos de 1990 e o fim da União Soviética, o Estado nacional era a unidade de análise quase natural, esse nacionalismo metodológico não funciona mais (Sassen, 2006); enquanto o ajustamento institucional entre as estruturas econômicas e políticas e, portanto, a possibilidade de domar o capitalismo era tida como certa, ao menos no mundo ocidental, as consequências atuais do avanço do assim chamado "neoliberalismo" levantaram sérias dúvidas sobre se essa era uma hipótese de algum modo razoável (Streeeck, 2013; Wallerstein, Collins, Mann, Derluguian e Calhoun, 2014); enquanto ao menos os cientistas sociais acreditaram por muito tempo no avanço da "racionalidade" na sociedade moderna (isto é, secular) e, portanto, na decadência da religião, eles atualmente precisam se dar conta de que as coisas podem caminhar em outro sentido, ao menos em outras partes do mundo; mais do que isso, o conceito de "secular", outrora considerado como tendo um significado claro, torna-se cada vez mais contestado, mesmo no interior da Europa (Calhoun, Juergensmeyere, Van Antwerpen, 2011). E, por fim, mas não menos importante: enquanto, no passado, os cientistas sociais ocidentais pareciam conhecer a exata significação de "modernidade", isso também se transformou velozmente. A rápida ascensão econômica da China, o avanço econômico de países como o Brasil, por exemplo, deixaram claro que será cada vez mais problemático falar em uma modernidade, que seria mais apropriado pensar em diferentes modernidades (no plural), embora não seja nada fácil descrever exatamente suas características (Eisenstadt, 2000; Domingues, 2013). Em segundo lugar, essas dificuldades analíticas e conceituais parecem crescer em virtude do enorme impacto da compreensão antropológica e do conhecimento histórico sobre as regióes "não ocidentais". Estas não podem mais ser ignoradas e, com isso, estão afetando quase que necessariamente o núcleo teórico das ciências sociais, estando em vias de solapar as premissas básicas tidas como autoevidentes desde os primórdios dessas disciplinas. Atualmente, em particular os teóricos pós-coloniais (que se valem desse conhecimento antropológico e histórico) estão questionando esse "núcleo", buscando demonstrar que termos sociológicos bem estabelecidos, e que reivindicam validade universal, em verdade não são aplicáveis em muitas partes do globo, porque elaborados sobre pressupostos ocultos originados no passado imperial euro-americano. Sendo assim, a questẫo formulada há alguns anos por Raewyn Connell ainda precisa ser respondida: "Podemos ter uma teoria social que não reivindique universalidade a partir de um ponto de vista metropolitano, que não seja interpretada em uma única direção, que não exclua a experiência e o pensamento social da maior parte da humanidade e que não seja construída sobre uma terra nullius?" (Connell, 2007, p. 47).

Este é o ponto em que estamos, e a situação aqui esboçada não é certamente muito confortável. As ciências sociais parecem estar sendo mais contestadas do que nunca, e os conflitos em seu interior, mais ferozes que os ocorridos durante os anos de 1970 e 1980 . Naturalmente, poder-se-ia deixar de lado a perturbadora questão de Connell afirmando simplesmente que formular uma questão crítica é 
sempre mais fácil do que respondê-la de maneira significativa, que desconstruir velhas teorias e conceitos veneráveis não é mais que o primeiro passo no projeto desafiador de desenvolver novas metodologias convincentes e construir teorias alternativas. $\mathrm{E}$, provavelmente, esse argumento não está equivocado, pois as teorias pós-coloniais ainda são mais convincentes quanto ao trabalho "desconstrutivo" que vêm realizando do que no tocante às tentativas de construir um corpo coerente de argumentos teóricos. Mas tal resposta à questão de Connell não seria muito produtiva com respeito a uma discussão frutífera. O desafio das teorias pós-coloniais deveria ser tomado mais a sério, uma vez que seus esforços construtivos são mais importantes e mais próximos às correntes dominantes do que muitas vezes se pensa. Isso se pode verificar em duas publicaçóes relativamente recentes de autores que, penso, estáo bem estabelecidos no campo pós-colonial.

Theory from the south: or, how Euro-America is evolving toward Africa [Teoria do sul: ou, como a Euro-América está evoluindo com relação à África], de Jean e John L. Comaroff, é certamente um livro provocativo, na medida em que seus autores, destacados antropólogos sul-africanos com forte interesse em teoria social, argumentam que o conceito de pessoa autônoma - que constituiu e constitui uma premissa central para as teorias da ação das tradiçóes teóricas presumivelmente mais importantes das ciências sociais - passa por enormes problemas na África do Sul (Comaroff e Comaroff, 2011, pp. 51-64), e provavelmente não apenas lá. O livro é ainda mais provocativo quando afirma que as mudanças e os fenômenos sociais recentes na África não devem ser interpretados como patologias a serem curadas e superadas por desenvolvimentos que levarão a estruturas muito similares às estruturas estáveis inventadas na Euro-América. Pelo contrário, é convicção dos autores que muitas dessas chamadas patologias na África têm que ser vistas como fenômenos com significância mundial e duradoura, na medida em que mostram à Euro-América seu próprio futuro. Os padróes e as características do capitalismo neoliberal e da globalização, dizem eles, podem ser estudados com mais proveito através de processos que ocorrem na periferia, porque mais cedo ou mais tarde eles aparecerão nos centros do capitalismo ocidental (Idem, pp. 12-19). Mesmo que não se concorde com essa e outras afirmaçóes dos Comaroff, e ainda que não se compartilhe de todas as suas intençóes polêmicas, devem-se, não obstante, apreciar os esforços teóricos e metodológicos construtivos desses autores. De modo bastante convincente, eles ressaltam que, para um melhor entendimento do mundo social, é necessário não assumir acriticamente conceitos hegemônicos que tão frequentemente se mostraram inúteis ou mesmo danosos quando aplicados a contextos não ocidentais. E aqui, argumentam, a visão antropológica de fora, da periferia, das margens, pode certamente ajudar a estabelecer esse efeito particular de "estranhamento crítico" (Idem, p. 19). Mas a Verfremdung, acrescentam imediatamente, não é algo que se faça por fazer. É antes um método (e, aqui, vêm fortemente à mente os argumentos de Robert Ezra Park, em meados do século XX, sobre o "homem marginal" [Parks, 1950]) para construir teoria a partir da base:

Por teoria, assinalamos, não entendemos a grande teoria no sentido da alta tradição modernista. Nosso voo não é para a pura abstração ou a antropologia filosófica. Queremos significar teoria fundamentada em dados [grounded theory]: um esforço historicamente contextualizado, orientado por problemas, para dar conta da produçáo de fatos sociais no mundo, recorrendo a um contraponto metodológico imaginativo entre o indutivo e o dedutivo, o concreto e o cotidiano, o concreto e o conceito [...] (Comaroff e Comaroff, 2011, p. 48, grifo no original).

Embora os Comaroff, em uma nota de rodapé, procurem distanciar-se imediatamente da abordagem sociológica, por certo metodologicamente "ocidental", tornada famosa, nos anos de 1960, por Barney G. Glaser e Anselm L. Strauss (1967), criticando-a por sua suposta "pureza indutiva" (Comaroff e Comaroff, 2011, nota 54), ${ }^{1}$ dificilmente se pode ignorar uma espécie de Vahlverwandtschaft (afinidade eletiva) entre a grounded theory original e a proposta pelos Comaroff. Não é de surpreender que se possam encontrar argumentos similar- 
mente estruturados na obra do sociólogo português Boaventura de Sousa Santos. Em uma declaração programática (em coautoria com João Arriscado Nunes e Maria Paula Meneses, 2008), ele também questiona uma ciência social ocidental que muitas vezes simplesmente negligencia e rejeita o saber dos atores locais e procura estabelecer-se como o único conhecimento válido e, portanto, legítimo. Como ressalta Santos, tal posição é difícil de ser defendida atualmente, porque o debate das últimas décadas sobre o status do conhecimento científico - debate tão fortemente moldado por acadêmicas feministas, entre outros - pôs em relevo a pluralidade interna da ciência (Santos, Nunes e Meneses, 2008, p. XXVL), o que, naturalmente, significa não haver uma e apenas uma verdade em toda parte. Mas, assim como os Comaroff, Santos não para por aí; em vez disso, procura também oferecer argumentos teóricos mais construtivos. De modo similar aos Comaroff, afirma que "uma perspectiva pós-colonial se vale da ideia de que as estruturas de poder e conhecimento são mais visíveis a partir das margens" (Idem, p. xxxiv). Porém, talvez com mais clareza que a de seus colegas sul-africanos, ele tem consciência de que a perspectiva das margens, por si só, náo garante a verdade. Para ele, falar sobre a verdade é de qualquer forma enganoso. Se esse é o caso, entretanto, a questão que imediatamente se coloca é a do relativismo, o problema de todos os pontos de vista serem encarados como igualmente válidos. Obviamente, Santos quer evitar tal conclusão relativista. Ele propóe uma agenda de pesquisa claramente relacionada com tópicos tratados pela sociologia do conhecimento de Karl Mannheim nos anos de 1920 - que póe suas esperanças na possibilidade e necessidade de traduçóes recíprocas [mutual translations] entre diferentes visóes de mundo, porque cada cultura, cada visão de mundo é inerentemente incompleta e, portanto, pode e deve ser enriquecida pela incorporação de perspectivas alternativas. Sendo assim, essa nova metodologia de pesquisa precisa ancorar-se na tradição hermenêutica, e é nela que Santos desenvolve sua marca diatópica:

O objetivo da hermenêutica diatópica não é, portanto, alcançar a completude - uma meta inalcançável -, mas, ao contrário, aumentar ao máximo possível a consciência da incompletude recíproca por meio do engajamento no diálogo, como que com um pé em uma cultura e o outro pé em outra. Nisso reside seu caráter diatópico (Santos, 2008, p. 16, grifo no original).

De novo, como no caso dos Comaroff, os esforços construtivos de um autor considerado um teórico pós-colonial conduzem a águas já navegadas por autores da tradição clássica das ciências sociais.

Isto me leva ao ponto principal de meu ensaio. Ao referir-me a argumentos recentes de teóricos pós-coloniais, não é minha intenção afirmar que eles estão apenas repetindo debates já ocorridos décadas atrás no interior da tradição clássica da sociologia. Ao mencionar Park, Mannheim ou a tradição hermenêutica, não estou dizendo que os teóricos pós-coloniais não sejam originais ou que se deveria ler melhor os chamados clássicos. Minha argumentação é diversa, na verdade é uma argumentação construtiva: separar estritamente a teoria pós-colonial da tradição sociológica clássica não é uma estratégia frutífera, posto haver consideráveis superposições e, portanto, possibilidades para intercâmbio intelectual. Se se compreende que nem a "teoria pós-colonial" nem a "tradição clássica" são correntes homogêneas e unidimensionais, mas muitas vezes constituem áreas intelectuais altamente contestadas e, portanto, heterogêneas, torna-se plausível a ideia de "tradução" entre pelo menos partes dessas "duas tradições". Isso é especialmente assim porque - como procurarei mostrar - alguns desenvolvimentos teóricos importantes, ou melhor, reconfiguraçôes significativas podem atualmente ser detectadas no discurso da chamada ciência social ocidental, o que pode ajudar a tornar tal movimento em direção à tradução mais fácil do que se poderia esperar à primeira vista.

Com base em argumentos originalmente levantados pelo sociólogo sueco Björn Wittrock, afirmo inicialmente que tais reconfigurações estão de fato ocorrendo no interior da teoria social ocidental, implicando mudanças relacionadas com percepção de que a vida social só pode ser entendida de um modo não determinístico, de um modo sensível às contingências (I). Essa perspectiva, algo 
nova, - e, na sequência, procurarei oferecer alguns esclarecimentos somente sobre minha disciplina, a sociologia - pode ser detectada inclusive naquelas subdisciplinas da sociologia, nas quais era originalmente muito forte a crença em forças sociais hiperestáveis, a saber, a sociologia econômica (economia política) e a sociologia histórica (II). Essa transformação teórica está de fato em marcha, o que leva a que algumas perguntas simples, mas ao mesmo tempo absolutamente centrais, tenham que ser formuladas e respondidas (III) - e isso exatamente de um modo que dê alguma esperança para uma espécie de convergência entre pelo menos partes da teoria social "tradicional" ou "ocidental" e as abordagens pós-coloniais (IV).

\section{I}

Que a chamada teoria social "ocidental” não é uma entidade homogênea e estável, mas antes heterogênea e em fluxo, é algo que foi discutido de maneira convincente por Björn Wittrock em um ensaio recente intitulado "Human action, history and social change: reconstruction of social theory in three contexts" [Ação Humana, História e Mudança Social: Reconstrução da Teoria Social em Três Contextos] (Wittrock, 2011). Nesse texto, originalmente publicado em alemão, Wittrock afirma que, desde o final dos anos de 1960, o debate teórico no interior da sociologia foi impulsionado por um conflito entre, por um lado, as concepçóes de tipo positivista sobre as ciências sociais, na tradição de Gustav Hempel e, por outro, as abordagens antipositivistas, na tradição dos últimos trabalhos de Ludwig Wittgenstein. Este estado belicoso, entretanto, não existe mais porque, segundo Wittrock, há importantes correntes teóricas em ascensão que prometem superar esse impasse. É possível observar sinais de convergência, fracos, mas detectáveis, entre campos teóricos outrora antagonistas, convergência que - como afirma - também pode ter sido causada por desenvolvimentos teóricos ocorridos em disciplinas vizinhas. Nesse ponto, Wittrock destaca especialmente o trabalho de Quentin Skinner, um dos protagonistas da chamada Escola de História Intelectual, de Cambridge, os quais, pela influên- cia de seus trabalhos, obrigaram os sociólogos a levar a sério as açóes e seus significados peculiares. Correndo o risco de excesso de simplificação, pode-se dizer que, para Wittrock, importantes correntes da teoria social estão se movendo no sentido de compreender a ação em um quadro teórico sensível ao significado em contextos específicos. Embora isso não elimine o status multiparadigmático da sociologia, essa convergência terá um impacto saudável sobre a teoria social ("ocidental"), visto que os debates nesse campo estão começando a parecer mais focados que há algumas décadas. Apoio a interpretação de Wittrock e apenas estenderei um pouco sua tese para afirmar que agora, implícita ou explicitamente, há um termo específico e crescentemente importante na agenda da teoria social que nos permite ter esperança em uma espécie de convergência não somente no interior da chamada teoria social ocidental, mas também entre essa própria tradição e os enfoques pós-coloniais tratados no início deste artigo. Esse termo é "contingência", e minha asserção é de que as ideias e problemas que lhe são próximos acabarão por se constituir em uma espécie de ponto de encontro inspirador, e (oxalá) pacífico, dos dois campos teóricos tantas vezes em conflito. Deixe-me elaborar mais sobre isso, oferecendo dois exemplos notáveis da macrossociologia ocidental, não apenas porque esse é o campo com o qual estou mais familiarizado, mas também porque essa é uma área de pesquisa em que os desenvolvimentos teóricos tiveram uma inflexão de certa forma surpreendente ${ }^{2}-$ algo que, por certo, interessa também às disciplinas adjacentes à sociologia.

\section{II}

Meu primeiro exemplo: em 2007, imediatamente antes da última grande crise econômica, Charles F. Sabel, um dos proeminentes cientistas sociais da Universidade de Colúmbia, em um ensaio quase profético - intitulado "Bootstrapping development: rethinking the role of public intervention in promoting growth" [Engendrando o desenvolvimento: repensando o papel da intervenção governamental na promoção do crescimento] -, argumentou que, apesar de uma longa tradição de 
pesquisa, é difícil defender a crença em uma base de conhecimento segura em economia política e sociologia econômica, visto não ser claro de modo algum que a eliminação das chamadas barreiras institucionais ao crescimento econômico produza de fato os processos desejados (Sabel, 2007, p. 317). No passado, o crescimento, eventualmente ocorrido após a implementação de programas nacionais de reformas, deu-se muito raramente de maneira espacialmente homogênea, iniciando-se muitas vezes localmente nos assim chamados núcleos de crescimento (Idem, p. 318) - o que constitui um forte indicador das incertezas cognitivas a respeito dos reais efeitos de tais programas. Sabel argumenta que essa escassez de conhecimento é ainda mais difícil de ser ignorada quando se dá conta de que muitos processos de reforma caracterizados por incompletudes, inconsistências e implementação fragmentada acabaram, não obstante, por revelar-se mais tarde bastante exitosos! Assim, a conclusão implícita de Sabel é de que, ao menos na esfera econômica, os cientistas sociais não apenas têm dificuldade em identificar processos robustos inequívocos, mas ainda maior dificuldade em explicá-los. Para alguém como eu, proveniente da Alemanha - que apenas há alguns anos era identificada como um país em dificuldades econômicas [the sick man of Europe] e que hoje, por quaisquer que sejam as razóes, parece ser uma espécie de Estado modelo na Europa -, tal argumento parece de fato muito plausível. A pista teórica propiciada por Sabel é de que, mesmo em campos bem pesquisados como a economia política ou a sociologia econômica, afirmaçóes teóricas muito gerais tornaram-se altamente problemáticas, posto que as realidades e os processos econômicos parecem ser mais complexos, desordenados e imprevisíveis do que a maioria dos teóricos está disposta a admitir. E, segundo entendo a argumentação de Sabel, a esperança de compreender a complexidade da realidade social por meio do desenvolvimento de modelos matemáticos cada vez mais complexos pode se revelar também um beco sem saída porque todos esses modelos não são capazes de levar em consideração nem as frequentemente surpreendentes decisóes dos atores nem os efeitos de eventos contingentes.
Meu segundo exemplo. Uma das discussóes mais estimulantes na sociologia atual ocorre na interseção entre a sociologia histórica, por um lado, e as correntes da historiografia conhecidas como "história mundial" ou "história global", por outro. Sem temor a maiores simplificaçóes, pode-se afirmar que esse debate diz respeito - e em que medida à sustentabilidade da imagem clássica da Europa e sua singularidade tal como propagada pelos pais fundadores da sociologia, ou se - dadas as percepções oriundas dos "historiadores globais" - são mais plausíveis interpretaçôes alternativas da história europeia e, consequentemente, perspectivas muito diferentes sobre o surgimento de sua modernidade. Como isto pode soar um tanto críptico para os não familiarizados com esses macrodebates, destacarei brevemente alguns argumentos da chamada California School of World History, ${ }^{3}$ cujo mais influente representante seja talvez Kenneth Pomeranz. Em 2000, esse autor, na época um renomado historiador da China na Universidade da Califórnia em Irvine, publicou um livro altamente inovador em termos metodológicos, intitulado The great divergence: China, Europe and the making of the modern world economy [A grande divergência: China, Europa e a construção da moderna economia mundial], no qual desafiou os clássicos da sociologia e, portanto, o senso comum sociológico em geral (Pomeranz, 2000). Ele argumentou que a Revolução Industrial inglesa e, em conexão com ela, a chamada ascensão do Ocidente e a subsequente decadência da China no final do século XVIII e início do século XIX devem ser interpretadas principalmente como resultantes de processos contingentes. Segundo ele, diferentemente do que afirmaram os sociólogos clássicos, a Revolução Industrial não foi uma espécie de resultado final lógico de processos iniciados muitos séculos antes de 1760 e que conduziram quase que necessariamente a um dinamismo econômico que culminou na Revolução Industrial. Esse é um quadro traçado por Max Weber e muitos de seus sucessores quando, em suas reconstruçóes históricas, se referem à tradição do direito romano, à ética do trabalho protestante, às estruturas estatais específicas da Europa e a muitas outras instituiçóes e processos - todos esses fenômenos presumivelmente precondições da ascensão posterior da Europa ao poder 
mundial. A posição de Pomeranz é muito diferente: utilizando um esquema comparativo específico por regiāo (que, entretanto, não discutirei aqui), ele argumenta que a ascensão da Inglaterra durante a Revolução Industrial se baseou essencialmente em duas condiçóes mais propriamente contingentes: a) o fácil acesso ao carvão, e b) a existência de um tipo específico de colônias na América do Norte e no Caribe que se tornaram um mercado florescente e, assim, um escoadouro muito necessário aos produtos da incipiente Revolução Industrial. Essas duas condiçôes estiveram ausentes na China, de modo que, no século XVIII, o significativo dinamismo econômico em partes do país, um processo não tão dissimilar ao ocorrido na Inglaterra, nunca culminou em uma "decolagem". O argumento principal de Pomeranz é de que foram circunstâncias basicamente contingentes as que conduziram ao avanço da Inglaterra! Mas a China poderia também ter sido o primeiro gigante industrial se algumas condiçóes houvessem sido diferentes $^{4}$. Meu propósito, aqui, não é afirmar que, por exemplo, Weber estava completamente equivocado e que a explicação de Pomeranz é completamente correta (Vries, 2013). Eu gostaria simplesmente de afirmar que Pomeranz, valendo-se de instrumentos mais propriamente convencionais de análise econômica, desafia com sucesso todas as macronarrativas baseadas no pressuposto de desenvolvimentos de longo prazo tão típicos da sociologia, em particular, e das ciências sociais, em geral.

Esses dois exemplos da sociologia econômica e histórica - e poderiam ser citados muitos mais, provenientes de outros campos - apontam para um problema específico. Desde o início, o objetivo da sociologia foi descobrir mecanismos entendidos como conexôes causais recorrentes que, de alguma forma, prometessem dar ordem à esmagadora complexidade da mudança social. Mas, ao menos seus praticantes e teóricos autorreflexivos foram repetidamente forçados a aludir a contextos e eventos mais contingentes que obviamente conformam os processos causais, ameaçando, assim, solapar qualquer pretensão - inclusive a sua própria - à elaboração de modelos e às generalizaçóes teóricas (Mayntz, 2002). Nessa situação algo aporética, inicia-se usualmente uma fala um tanto impotente sobre "sistemas complexos", que obviamente não seguem uma "regra detectável", e termos como "interferências", "efeitos coincidentes" ou "efeitos Cournot" são crescentemente usados para explicar por que as regularidades não são de modo algum tão regulares. É como se a sociologia como disciplina quisesse acreditar firmemente em uma ontologia que sustenta ser a vida social simplista e regular.

Penso que há boas razóes para criticar tal crença e levar mais a sério um antigo argumento filosófico que, na filosofia atual, em meu conhecimento, foi apresentado de maneira muito vigorosa por Alasdair MacIntyre há cerca de trinta anos. A sugestão teórica do argumento de MacIntyre não é de que não haja regularidades na vida social. Ele sabe e nós todos sabemos muito bem que tais regularidades existem porque, na vida cotidiana, podemos fazer planos que efetivamente funcionam e porque simplesmente há correlaçóes estatísticas que se mostram bastante robustas. Mas, ao mesmo tempo, também é verdade que a vida social se caracteriza por inovaçóes - por processos e eventos radicalmente novos que não são previsíveis apenas por razóes lógicas. Não podem ser previstos porque uma descrição precisa da invenção que se supóe que ocorrerá no futuro já constitui a própria invenção. Além disso, nem atores nem observadores podem predizer "coisas" sobre as quais ainda não tenham decidido, e o destino cego [blind fate] exerce um papel importante na ação e interação humanas. Assim, a imprevisibilidade é uma das condiçóes ontológicas da humanidade, o que leva MacIntyre a sustentar, de um modo ainda mais provocativo (pelo menos para a maioria dos cientistas sociais), ser ela uma das características da vida humana que produz continuamente contraexemplos a tendências e leis supostamente fixas (MacIntyre, 1981). Ou, para dizê-lo de outra forma, a contingência parece ser uma característica da vida social que não pode ser suprimida, embora os representantes da corrente dominante das ciências sociais, na verdade, sempre tentem fazê-lo! Em sua busca por leis e regularidades, eles tentaram e tentam, repetidamente, empurrar as contingências para as margens de suas análises ou mesmo tentam esquecer-se delas e, assim, necessariamente fracassam em suas tentativas de entender o surgimento de fenômenos novos. 
Obviamente, os cientistas sociais podem não se convencer de imediato por argumentos trazidos à baila por um filósofo. Mas, não são eles plausíveis? Pense-se somente no destino que tiveram muitos dos termos processuais da disciplina que prometeram ter um valor tanto explicativo como preditivo: todas aquelas “-izaçôes”. Quâo autoconfiantes estavam os cientistas sociais quando falavam em "modernização", nos anos de 1950 e 1960 , e veja-se o quão problemático esse termo se tornou! (Knöbl, 2001b). Com quanta segurança era utilizado o termo "secularização" - e quantas exceçôes, desvios etc. são discutidos agora! (Taylor, 2007; Casanova, 2006) Não é muito diferente quanto à "democratização" (Mann, 2005), à “individualização" (Araújo e Martuccelli, 2012) etc. E quão vigoroso virá a ser o termo "globalizaçáo"?

\section{III}

Se for ao menos plausível que "contingência" parece tornar-se um dos pontos de referência mais importantes dos debates teóricos (e, por certo, não apenas na macrossociologia), é então forçoso fazer algumas perguntas aparentemente simples - algumas delas relacionadas com o já mencionado ensaio de Björn Wittrock. A primeira é a seguinte: de que tipo de teoria da açâo precisamos para dar conta do caráter contingente da realidade social? Não há uma resposta definitiva para esta questão, mas se poderia afirmar com certeza que os motivos que atribuímos aos atores sociais, os modelos teóricos de ação que construímos, não deveriam ser tão simplistas ${ }^{6}$. A esse respeito, nâo se pode deixar de endossar a alegação implícita de Wittrock de que é preciso levar a sério os significados de açôes muitas vezes bastante diferentes em termos religiosos, culturais e econômicos, de que se deve elaborar sobre os insights provenientes da história conceitual de Quentin Skinner, mas também dos oriundos da antropologia e mesmo da teoria literária. Os sociólogos não deveriam, portanto, emular a corrente dominante da economia, tentando desenvolver modelos matemáticos baseados em hipóteses bastante audaciosas, mas também altamente dúbias. Nesse aspecto, estou também fortemente convencido de que o conhecimento sobre a história da sociologia e disciplinas adjacentes pode ajudar muito. Desde os primórdios das ciências sociais, observaram-se ondas recorrentes de intentos no sentido de tornar a sociologia mais científica, de emular a física, a química ou a biologia como as únicas e verdadeiras ciências. Quer seja a ambição dos marxistas de descobrir as leis da história, o empenho de alguns teóricos da ação em construir a disciplina com base na teoria da explicação causal de Gustav Hempel, a tentativa estruturalista de promover a linguística como ciência líder, ou - em um campo diferente, simultaneamente - a declaração da teoria geral dos sistemas ou da biologia como o ideal da sociologia, todas essas tentativas fracassaram e o legado dessas teorias sociais, outrora altamente influentes, não é de modo algum impressionante. Então, por que acreditar em novas promessas de uma idade de ouro da sociologia se esta viesse a basear suas teorias apenas em uma base sólida? Não há nenhuma, ao menos não no sentido de que se pudesse encontrar a essência mesma da sociologia na metodologia de uma ciência aparentemente "real", seja ela a matemática, a biologia ou a economia!

Naturalmente, referir-se à "ação" não significa necessariamente endossar a específica teoria da ação de Max Weber. Trata-se simplesmente do argumento geral - e aqui é de novo importante a referência de Wittrock à obra de Quentin Skinner - de que é preciso levar a sério o contexto e o significado da ação [agency], de que - e aqui entram em jogo a questão da "tradução", como enfatizou Souza Santos, e as observaçóes dos Comaroff sobre a "pessoa" é preciso mesmo historicizar e contextualizar o conceito de ator.

Concluindo este ponto com uma observação geral, enfatizo que a convergência teórica está de fato a caminho quando até mesmo os macrossociólogos, em virtude da existência de contingências, são forçados a produzir teorias da ação um tanto sofisticadas que, até agora, na maioria das vezes, foram endossadas apenas por sociólogos trabalhando com a perspectiva micro (Deutschmann, 2011).

De que tipo de metodologia precisamos para compreender o caráter contingente da realidade social? 
Penso que, a partir dos exemplos mencionados aqui, podemos aprender que a sociologia irá caminhar, e já está caminhando, na direção de algo que, tempos atrás, William Sewell denominou como uma "sociologia de acontecimentos" [eventful socio$\log y$ ] (Sewell, 1996). Quando muitos desses termos processuais, essas “-izaçóes”, são postos em dúvida, precisamos ficar muito mais conscientes da possibilidade de certos atores serem capazes de romper, reverter e, portanto, pôr fim a processos sociais. Devemos ser mais céticos em relação às afirmaçóes da existência de tendências de longo prazo supostamente robustas e a suas explicações, em relação a declaraçôes ousadas sobre a lógica funcional dos sistemas etc. Tomando o já mencionado exemplo de Charles Sabel sobre agendas de reforma econômica: quando simplesmente não estamos seguros sobre o que provocou o crescimento econômico, local ou nacionalmente, nossas narrativas devem ser tentativas e cautelosas, e devem ser modestos os nossos termos e conceitos. Pode haver regularidades bem provadas e processos robustos, mas acontecimentos contingentes estão por toda parte, o que significa também que esses próprios acontecimentos poderiam explicar o resultado do processo, assim como, pelas mesmas razóes, outros acontecimentos em determinado ponto poderiam interromper ou reverter tal processo supostamente robusto.

Na última década, vimos um animado debate teórico sobre as "variedades de capitalismo" (Hall e Soskice, 2001) e um debate metodológico sobre "dependência de trajetória" [path dependency] (Mahoney, 2000). Ambos os debates prometiam romper com a crença sociológica em processos de longo termo e de grande robustez, pois o discurso não era mais sobre o "capitalismo" em geral, mas sobre diferentes tipos de capitalismo e processos de capitalização; o objeto de discussão não era mais um processo geral, mas diferentes processos com pontos de partida variáveis e conjunturas críticas. Mas, ainda assim - como vimos -, esses debates, inicialmente muito excitantes, perderam o momentum, porque ocorreu que mesmo os tipos aparentemente robustos de capitalismo nacional estavam em vias de mudança e que mesmo os processos posteriores a pontos de partida e conjunturas críticas eram mais frágeis do que se supunha inicialmente.
De novo, o que acontece é que a ontologia da realidade social é mais complexa do que a maioria dos cientistas sociais está disposta a admitir, de modo que temos simplesmente que levar a sério os acontecimentos - e náo apenas os processos. E se isso é verdadeiro, temos então que refletir muito mais sobre como narrar a realidade, como fazer uma "sociologia dos acontecimentos", como sugeriu Sewell.

Como sabemos, há diferentes maneiras de narrar e apresentar um relato plausível de acontecimentos e processos. $\mathrm{E}$ as ciências sociais certamente não chegarão a um consenso metodológico sobre narrativas adequadas - eu diria que esta é seguramente uma previsão robusta! Mas o que precisamos evitar em quaisquer circunstâncias é contar histórias de maneira que descreva processos como se fossem dirigidos por uma espécie de "código genético", como expressou o cientista político e sociólogo francês Michel Dobry (1999). Há sempre perigo em examinar processos a partir da perspectiva de seus resultados finais, como se - para usar um dos exemplos de Dobry - a existência de regimes democráticos plenamente desenvolvidos na Europa do Leste atual fossem o resultado necessário dos primeiros clamores por democratização quando a Uniāo Soviética ainda existia. Isso é raciocínio teleológico da pior espécie, mas certamente não incomum em nossa disciplina. $\mathrm{O}$ único meio contra tais teleologias é levar a sério atores e constelações de atores.

Como cientistas sociais, de que tipo de autocompreensáo ou de identidade precisamos para dar conta do caráter contingente da realidade social? Gostaria de enfatizar aqui dois pontos que, segundo entendo, não são apenas resultados de meus desejos idiossincráticos, mas já podem ser vistos na maneira pela qual as ciências sociais estão sendo cada vez mais praticadas neste momento. (A) Se existem razões plausíveis para crer que "contingência" é um dos termos centrais com que as ciências sociais cada vez mais terão que lidar, então será preciso que elas historicizem inteiramente seus próprios termos e conceitos, ao menos todas aquelas “-izaçóes" já mencionadas. Por que Max Weber, por exemplo, criou tantos termos processuais excessivamente robustos - como "racionalização", entre outros -, termos, aliás, em relação aos quais parece ter-se 
contradito em suas muito mais refinadas e brilhantes análises históricas sobre constelaçôes de atores? Qual foi o pano de fundo político e disciplinar de tal posição aparentemente inconsistente? (Knöbl, 2001a). Essas e outras questóes precisam ser respondidas, o que, ao mesmo tempo, significa que a tarefa de historicizar conceitos não deve ficar apenas para os historiadores, mas devem tornar-se uma das preocupaçóes principais da teoria social. Voltando ao já mencionado ensaio de Wittrock, nós precisamos de mais Skinners nas ciências sociais e na teoria social, e, naturalmente, devemos também incorporar as críticas muitas vezes brilhantes dos teóricos pós-coloniais. Por conseguinte, argumento que enfatizar a importância da história da teoria social e de seus conceitos não é sinal de um status pré-científico das ciências sociais, mas a principal precondição para o progresso teórico e - eventualmente - a convergência. (B) A importância das contingências deveria também tornar os cientistas sociais mais modestos em suas afirmações críticas. Se os cientistas sociais enfrentam imensas dificuldades para explicar processos sociais de larga escala como terá mostrado o já mencionado exemplo de Charles F. Sabel -, é preciso que eles tenham consciência de que fazer o diagnóstico de nosso tempo é, na verdade, um assunto que envolve imenso risco. Penso que essa percepção está ganhando aceitação crescente em correntes importantes das humanidades e das ciências sociais. Se, por exemplo, os pós-estruturalistas estão argumentando, de maneira pós-fundamentalista, em favor de fundamentos contingentes de todo sistema de pensamento (Marchart, 2010), de toda filosofia, isso não é, então, muito diferente da "sociologia da crítica" de Luc Boltanski e Laurent Thevenot (1991). Se nós não temos, e não iremos nunca conseguir, uma teoria única explicativa da sociedade - na qual os membros da Escola de Frankfurt atual, como Axel Honneth, ainda parecem acreditar, ${ }^{7}$ na medida em que ainda reivindicam para si próprios a condição de serem (os únicos) "teóricos críticos" -, então os sociólogos da tradição muito mais modesta de Boltanski/Thevenot têm de fato melhores argumentos a seu favor. A propósito, Boltanski e Thevenot propóem uma sociologia da crítica, em vez de uma sociologia crítica, porque somente a primeira pode levar a sério o potencial crítico de atores reais. Isso me leva à próxima e última parte deste artigo, na qual faço alusão à possível "tradução" mútua dos problemas da teoria pós-colonial, por um lado, e da teoria social na tradição dos clássicos das ciências sociais, por outro.

\section{IV}

Creio, de fato, que a teoria pós-colonial compartilha algumas das preocupaçóes de pelo menos partes do pensamento social "tradicional ocidental”. Uma estratégia de construção teórica como a que se segue, sugerida pelos Comaroff, deveria e poderia encontrar defensores não apenas no interior dos círculos pós-coloniais:

[...] nossa predileção é por uma teoria que não seja nem uma metanarrativa extremamente abrangente, nem [uma teoria] microscopicamente, miopemente, local, mas que se situe na difícil escala entre as duas, procurando explicar os fenômenos tanto com referência à sua determinação mais ampla como à sua condição mais próxima, contingente - perscrutando os complexos, muitas vezes contra intuitivos, pontos de articulação entre elas (Comaroff e Comaroff, 2011, p. 48, grifo do autor).

Tal posição, como formulada por esses antropólogos, certamente não está demasiado distante do ponto de vista circunscrito por minhas respostas às questôes formuladas na secção anterior; questóes essas levantadas para chegar a um entendimento sobre o fenômeno da contingência, o qual parece ser cada vez mais reconhecido como um, se não o, desafio para os teóricos sociais na tradição ocidental clássica. Em outras palavras: historicizar conceitos centrais, no espírito de Quentin Skinner, por exemplo, não deveria ser uma tarefa a que os teóricos pós-coloniais devessem necessariamente se opor, ainda que isso signifique que suas próprias observações críticas, frequentemente impetuosas, sobre as instituiçóes ocidentais tenham que ser repensadas, ao menos na medida em que tais críticas se utilizam, sem muito cuidado, de termos a-históricos e 
altamente abstratos como "neoliberalismo", "capitalismo global” etc. ${ }^{8}$ Além disso, os teóricos pós-coloniais devem levar em conta que o ceticismo com relação às ambiçóes dos adeptos das grandes teorias e com respeito a uma metodologia "inspirada pela mecânica newtoniana e baseada no matematismo como o ideal de cientificidade" (Santos, Nunes e Meneses, 2008, p. xxx) pode ser encontrado também em autores inspirados pela sociologia clássica, de modo que, mais uma vez, há chances de um diálogo frutífero. Embora seja verdade que os enfoques pós-coloniais são muito influenciados por argumentos estruturalistas e pós-estruturalistas e, assim, procurem afastar-se da ideia de um ator autônomo, não deveria ser impossível controlar as reações um tanto alérgicas dos teóricos pós-coloniais a todas as abordagens teóricas da ação quando eles se dão conta, mais cabalmente do que antes, das enormes diferenças entre as teorias da ação. Portanto, a "tradução" é possível, especialmente se as teorias da ação "tradicionais" também levarem a sério aquelas passagens do livro mais recente dos Comaroff, em que os autores criticam a suposta universalidade do conceito de "pessoa" (2011, nota 35). Se os membros dos campos teóricos aparentemente em conflito estão realmente procurando construir pontes de modo a poderem conversar entre si, então há de fato esperança de que - paradoxalmente - as ciências sociais cada vez mais globalizadas se recusarâo explicitamente a seguir a corrente dominante na ciência econômica, com sua confiança nos métodos estandardizados e nas grandes teorias descontextualizadas; ao contrário, será a supramencionada convergência teórica que permitirá fazer uso da rica herança cultural e histórica do mundo com vistas a alcançar uma melhor compreensão dos fenômenos e dos processos sociais no período pós-hegemonia ocidental.

\section{Notas}

$1 \mathrm{O}$ mencionado distanciamento com relação à posição de Glaser/Strauss é de alguma forma justificável, já que os Comaroff afirmam estarem também interessados em questóes teóricas mais amplas, deixando claro que pretendem investigar a relação "entre o épi- co o cotidiano, o significativo e o material - e, neste caso em particular, entre capitalismo e modernidade, a dialética que se ajusta [fitful] ao núcleo de nossas preocupaçôes atuais" (Comaroff e Comaroff, 2011, p. 48). Mas os acadêmicos ligados à tradição de Glaser/ Strauss poderiam questionar se os termos "capitalismo" e "modernidade" constituem realmente bons pontos de partida para a análise social, posto que esses conceitos são certamente datados [have a time-index] e convidam a interpretaçôes muito diferentes.

2 Os sociólogos de orientação microssociológica estão, de algum modo, mais inclinados a crer nas estruturas contingentes e nos resultados das interaçóes face a face, de maneira que não me ajudaria muito citar exemplos desse campo para produzir um argumento convincente com relação a tendências nas ciências sociais e na teoria social em geral.

3 Sob esse rótulo, Jack A. Goldstone indicou autores que, na macrossociologia, dão sustentação ao projeto de uma crítica à tese de uma ascensão necessária do Ocidente (ele usa esse rótulo para si próprio e para autores como Kenneth Pomeranz, R. Bin Wong, André G. Frank, J. M. Blaut, James Abu-Lughod, entre outros). Tais autores são conhecidos como membros da Escola da Califórnia, porque "em sua maioria estáo afiliados a universidades daquele estado, mas nela se incluem acadêmicos de um lado a outro dos Estados Unidos e de outras partes do mundo" (Goldstone, 2000, p. 179). Com relação aos autores da Escola da Califórnia, Victor Lieberman fala sobre uma "mudança [argumentativa] de cultura para contingência", na medida em que os californianos rejeitam "a alegaçáo teleológica central dos excepcionalistas europeus, a saber, que o êxito singular do Ocidente se fundou em sua herança institucional e legal" (Lieberman, 2003, p. 72).

4 Naturalmente, o fato de que a Grã-Bretanha possuísse colônias não deve ser considerado um fenômeno contingente. $\mathrm{Na}$ macrossociologia, tal fenômeno deveria ser tratado antes sob a rubrica de "transferência", na medida em que a questáo levantada aqui é se o desenvolvimento da Grã-Bretanha (e da "Europa” e/ou do Ocidente) pode ser considerado como um processo endógeno (cf. Knöbl, 2007, p. 179).

5 "Há dois problemas com o conceito de globalização, primeiro o 'global' e segundo a '-ização"' (Cooper, 2005, p. 91). Para todo o complexo referente a essas “-izaçōes”, ver Joas (2012a e b).

6 Estou negligenciando aqui a questão de o termo "ação" pressupor ou não um entendimento etnocêntrico e ocidental de uma pessoa autônoma, de modo 
que se deveria falar mais propriamente de práticas sociais (ver Rackwitz, 2003, p. 296).

7 Ver, por exemplo, o último livro de Axel Honneth, Das Recht der Freiheit: Grundriss einer demokratischen Sttlichkeit (2011).

8 Ver nota 1, supra.

\section{BIBLIOGRAFIA}

ARAÚJO, Kathya \& Martuccelli, Danilo. (2012), Desafios communes: retrato de la sociedad chilena y sus individuos. Santiago do Chile, Lom Ediciónes, tomos 1 e 2.

BOLTANSKI, Luc \& THEVENOT, Laurent. (1991), De la justification: les économies de la grandeur. Paris. Gallimard.

CALHOUN, Craig; JUERGENSMEYER, Mark \& Van Antwerpen, Jonathan (eds.). (2011), Rethinking secularism. Oxford, Oxford University Press.

CASANOVA, José. (2006), "Rethinking secularization: a global comparative perspective". The Hedgehog Review, 8: 7-22.

COMAROFF, Jean \& COMAROFF, John L. (2011), Theory from the South: or, how Euro-America is evolving toward Africa. Boulder, Paradigm.

CONNELL, Raewyn. (2007), Southern theory: the global dynamics of knowledge in social science. Cambridge, Polity Press.

COOPER, Frederick. (2005), Colonialism in question: theory, knowledge, history. Berkeley/Londres, University of California Press.

DEUTSCHMANN, Christoph. (2011), "A pragmatist theory of capitalism". Socio-Economic Review, 9: 83-106.

DOBRY, Michel. (1999), "Paths, choices, outcomes, and uncertainty: elements for a critique of transitological reason", in (org.), Democratic and capitalist transitions in Eastern Europe: lessons for the social sciences, Dordrecht/ Boston/Londres, Kluwer Academic Publishers, pp. 49-70.

DOMINGUES, José Maurício. (2013), Global modernity, development and contemporary civilization. Londres, Routledge.

EISENSTADT, S. N. (2000), Die Vielfalt der Moderne. Weilerswist, Velbrück.
GLASER, Barney G. \& Strauss, Anselm L. (1967), The discovery of grounded theory: strategies for qualitative research. Nova York, Aldine de Gruyter.

GOLDSTONE, Jack A. (2000), "The rise of the West - or not? A revision to socio-economic history". Sociological Theory, 18: 179.

HALL, Peter A. \& SOSKICE, David S. (orgs.). (2001), Varieties of capitalism: the institutional foundation of comparative advantage. Oxford, Oxford University Press.

HONNETH, Axel. (2011), Das Recht der Freiheit: Grundriss einer demokratischen Sttlichkeit. Frankfurt-Main, Suhrkamp.

JOAS, Hans (2012a), "Gefährliche Prozessbegriffe: Eine Warnung vor der Rede von Differenzierung, Rationalisierung und Modernisierung”, in Karl Gabriel, Christel Gärtner e Detlev Pollak (orgs.), Umstrittene Säkularisierung Soziologische und historische Analysen zur Differenzierung von Religion und Politik, Berlim, Berlin University Press, pp. 603-622.

. (2012b), Glaube als Option: Zukunftsmöglichkeiten des Christentums. Freiburg im Breisgau, Herder, pp. 106-128.

KNÖBL, Wolfgang. (2001a), "Makrotheorie zwischen Pragmatismus und Historismus", in Bettina Hollstein, Matthias Jung e Wolfgang Knöbl (orgs.), Handlung und Erfahrung: Das Erbe von Historismus und Pragmatismus und die Zukunft der Sozialtheorie, Frankfurt-Main/Nova York, Campus, pp. 273-315.

. (2001b), Spielräume der Modernisierung: Das Ende der Eindeutigkeit. Weilerswist, Velbrueck.

. (2007), Die Kontingenz der Moderne: Wage in Europa, Asien und Amerika. Frankfurt-Main/Nova York, Campus.

LIEBERMAN, Victor. (2003), Strange parallels: Southeast Asia in global context, c. 1800-1830. Vol. 1: Integration on the mainland. Cambridge, Cambridge University Press.

MACINTYRE, Alasdair. (1981), After virtue: a study in moral theory. 3. ed. Notre Dame, Indiana, University of Notre Dame.

MAHONEY, James. (2000), "Path dependency in historical sociology". Theory and Society, 29: 507-548. 
MANN, Michael. (2005), The dark side of democracy: explaining ethnic cleansing. Cambridge, Cambridge University Press.

MARCHART, Oliver. (2010), Die Politische Differenz: Zum Denken des Politischen bei Nancy, Lefort, Badiou, Laclau und Agamben. Frankfurt-Main, Suhrkamp.

MAYNTZ, Renate. (2002), “Zur Theoriefähigkeit makro-sozialer Analysen", in Renate Mayntz, Akteure-Mechanismen - Modelle. Zur Theoriefähigkeit makro-sozialer Analysen. Frankfurt-Main/Nova York, Campus, pp. 7-43.

PARKS, Robert Ezra. (1950), "Human migration and the marginal man”, in (org.), Race and culture. Glencoe, The Free Press, pp. 345-356.

POMERANZ, Kenneth. (2000), The great divergence: China, Europe and the making of the modern world economy. Princeton/Oxford: Princeton University Press.

RACKWITZ, Andres (2003), "Grundelemente einer Theorie sozialer Praktiken: Eine sozialtheoretixche Perspectktive”. Zeitschrift für Soziologie, 32 (4): 282-301.

SABEL, Charles F. (2007), "Bootstrapping development: rethinking the role of public intervention in promoting growth", in Victor Nee e Richard Swedberg (orgs.), On capitalism, Stanford, Stanford University Press.

SANTOS, Boaventura de Sousa. (2008), "Human rights as an emancipatory script? Cultural and political conditions", in (org.), Another knowledge is possible: beyond Northern epistemologies, Londres/Nova York, Verso.

SANTOS, Boaventura de Sousa; NUNES, João Arriscado \& MENESES, Maria Paula. (2008), "Introduction: opening up the canon of knowledge and recognition of difference", in Boaventura de Sousa Santos (org.), Another knowledge is possible: beyond Northern epistemologies, Londres/Nova York, Verso, pp. XIX-LXII.

SASSEN, Saskia. (2006), Territory - Authority Rights. From medieval to global assemblages. Princeton, Princeton University Press.

SEWELL, William H. (1996), "Three temporalities: toward an eventful sociology", in Terrence
J. McDonald (org.), The historic turn in the human sciences, Ann Arbor, University of Michigan Press, pp. 245-280.

STREECK, Wolfgang. (2013), Gekaufte Zeit: Die vertagte Krise des demokratischen Kapitalismus. Berlim, Suhrkamp.

TAYLOR, Charles. (2007), A secular age. Cambridge, Mass./Londres, The Belknap Press of Harvard University Press.

VRIES, Peer. (2013), Ursprünge des nodernen Wirtschafswachstums: England, China und die Welt in der Frühen Neuzeit. Göttungen, Vandenhoeck \& Ruprecht.

WALLERSTEIN, Immanuel; COLLINS, Randall; Mann, Michael; DERLUGUIAN, Georgi \& CALHOUN, Craig. (2014), Does capitalism have a future? Oxford, Oxford University Press.

WITTROCK, BJörn. (2011), "Menschliches Handeln, Geschichte und sozialer Wandel: Rekonstruktion der Sozialtheorie in drei kontexten", in Bettina Hollstein, Matthias Jung e Wolfgang Knöbl (orgs.), Handlung und Erfahrung. Das Erbe von Historismus und Pragmatismus und die Zukunft der Sozialtheorie, Frankfurt-Main/Nova York, Campus, pp. 343-375. 


\section{RECONFIGURAÇÓES DA TEORIA SOCIAL APÓS A HEGEMONIA OCIDENTAL}

\section{Wolfgang Knöbl}

Palavras-chave: Teoria Social; Teorias Pós-Coloniais; Hegemonia Ocidental; Modernidade.

Nas últimas três décadas, os cientistas sociais tiveram de aprender que as hipóteses concernentes à robustez e à estabilidade dos processos e estruturas sociais não podem mais ser tidas por auto evidentes, posto que os resultados das açóes sociais são muito mais imprevisíveis do que usualmente se supunha e os acontecimentos e sua ocorrência inesperada devem ser levados em conta para se compreender a realidade social. Se isso está correto, a teoria social precisa repensar alguns de seus pressupostos metodológicos e teóricos básicos. Este artigo tratará das seguintes questóes: De que teoria da ação necessitamos para dar conta das características contingentes da vida social? Que tipos de relatos podem fazer os cientistas sociais com vistas a compreender essa mesma realidade? Podem os cientistas sociais falar ainda confiantemente em leis ou mecanismos sociais gerais ou devem eles basear-se mais propriamente em métodos narrativos? A resposta principal a essas questóes será a de que, na verdade, a teoria social terá que tomar em consideraçáo o problema da "narratividade", o que ao mesmo tempo significa que a corrente dominante da teoria social terá necessariamente que historicizar completamente todas as suas categorias.

\section{RECONFIGURATIONS OF SOCIAL THEORY AFTER WESTERN HEGEMONY}

\section{Wolfgang Knöbl}

Keywords: Teoria social; Teorias póscoloniais; Hegemonia ocidental; Modernidade.

In the last three decades social scientists had to learn that assumptions concerning the robustness and stability of social processes and structures cannot be held as self-evident any longer since the outcomes of social actions are far more unpredictable than is usually assumed and that events and their surprising occurrence have to be taken into account in making sense of social reality. If this is so, then social theory has to rethink some of its basic methodological and theoretical assumptions. The paper will address the following questions: Which theory of action do we need in order to come to terms with the contingent features of social life? Which types of accounts can social scientists give in order to grasp this very reality? Can social scientists still speak self-confidently of laws and/or general social mechanisms or must they rather rely on narrative methods? The main answer given to these questions will be that social theory indeed will have to take on the problem of "narrativity" which at the same time also means that main stream social theory will necessarily have to thoroughly historicize all its categories.

\section{RECONFIGURATIONS DE LA THÉORIE SOCIALE SUITE À L'HÉGÉMONIE OCCIDENTALE}

Wolfgang Knöbl

Mots-clés: Théorie sociale; Théories postcoloniales; Hégémonie occidentale; Modernité.

Au cours de ces trois dernières décennies, les spécialistes en sciences sociales ont dû apprendre que les hypothèses concernant la robustesse et la stabilité des structures et des processus sociaux ne pouvaient plus être considérées comme évidentes car les résultats des actions sociales étaient beaucoup plus imprévisibles que ce qui était habituellement considéré et que la production surprenante d'événements devait être prise en compte pour donner un sens à la réalité sociale. En assumant que cela soit correct, la théorie sociale devra alors repenser quelquesunes de ses hypothèses théoriques et méthodologiques de base. L'article abordera les questions suivantes : de quelle théorie d'action avons-nous besoin afin de nous réconcilier avec les caractéristiques du contingent de la vie sociale ? Quels types de résultats les spécialistes en sciences sociales peuvent proposer en vue de saisir cette réalité ? Est-ce que les sociologues peuvent encore parler avec précision des lois et/ou de mécanismes sociaux généraux ou devraient-ils plutôt s'appuyer sur des méthodes narratives ? La principale réponse proposée à ces questions est que la théorie sociale devra en effet se pencher sur le problème de la "narrativité ", ce qui signifie que la théorie sociale du courant principal devra nécessairement historiciser soigneusement toutes ses catégories. 